\title{
The Effect of Dissolved Nitrogen on the Fatigue Behavior of Ti-6Al-4V
}

\author{
C.R. COLLINS, F.F. DEAR, D. RUGG, and D. DYE
}

The effect of nitrogen additions on fatigue behavior has been examined in near-equiaxed, rolled Ti-6Al-4V bar. This is the first-time nitrogen content that has been systematically explored with respect to monotonic and cyclic properties in a Ti-6Al-4V alloy base composition. Nitrogen additions were found to increase the $\beta$-transus temperature and strength, but they decreased ductility, even in microstructures where some $\beta$ phase remained. This carried across into both the low- and high cycle fatigue behavior; even small contents of 240 and 560 ppmwN caused reductions in both low cycle fatigue life and high cycle fatigue strength. In samples containing 240 and 560 ppmwN, a conventional striated fractographic appearance was observed, but a dramatic change to a macroscopically brittle fracture surface was observed at 1800 and 3600 ppmwN, but still with substantial evidence of plasticity at the microscale. Therefore, neither microstructure or fractographic examination, nor EDX-based compositional analysis in the electron microscope are necessarily a reliable indicator of an absence of deleterious nitrogen contamination. This is significant for the investigation of potentially nitrogen-contaminated surface-initiated cracks, either due to service or processing exposures.

https://doi.org/10.1007/s11661-021-06147-2

(C) The Author(s) 2021

\section{INTRODUCTION}

Titanium is widely used in aerospace applications, where despite its notch sensitivity, it is prized for the high fatigue-allowable specific strengths that can be obtained, particularly in high cycle fatigue. These properties are a consequence of aerospace melt practice and high reactivity of molten titanium reducing the probability of defects and to its density, rather than the fatigue crack growth threshold or toughness, both of which are poorer than those found, e.g., in landing gear steels such as A300M. ${ }^{[1]}$

There is a wealth of knowledge and published data exploring the effects of oxygen on titanium alloys; however, nitrogen has received significantly less attention. Work was undertaken in the $1950 \mathrm{~s}^{[2-6]}$ on the effects of nitrogen on titanium alloys, but these data are limited in scope and availability of advanced experimental techniques, e.g., to yield strength and hardness

C.R. COLLINS is with the Department of Materials, Royal School of Mines, Imperial College, Prince Consort Road, South Kensington, London SW7 2BP, UK and also with Rolls-Royce plc, PO Box 31, Derby DE24 8BJ, UK. F.F. DEAR and D. DYE are with the Department of Materials, Royal School of Mines, Imperial College. Contact e-mail: david.dye@imperial.ac.uk D. RUGG is with RollsRoyce plc.

Manuscript submitted September 9, 2020; accepted December 30, 2020.

Article published online March 3, 2021 data, with little or no public data being available on the fatigue implications.

This is important because the high-temperature solid-state processing of titanium can lead to the introduction of interstitial-enriched surfaces. Usually these are mitigated through finishing operations and/or processing in a vacuum or inert atmosphere; however, guaranteeing complete removal of interstitial-enriched surfaces is not trivial. The local properties that occur at the surface of a titanium component, particularly around a geometric feature that may act as a stress raiser, will then often form the basis of the assessment of fitness for service. In such conditions, elevated levels of oxygen and/or nitrogen may be found, as both these elements have significant solubility in HCP $\alpha$-titanium. The effects of interstitials in titanium have been extensively reviewed by Conrad ${ }^{[7]}$; in general terms both oxygen and nitrogen are $\alpha$ stabilizers that provide solid solution strengthening to the $\alpha$ phase, and oxygen is added for this reason to many titanium alloys. However, there is an upper bound of useful oxygen content; for Ti-6Al-4V, this is $\leq 2400$ ppmwO.

The addition of oxygen and nitrogen to titanium alloys has been shown to increase the strength by a very large amount per at. pct (Figure 1); this also has the undesired effect of embrittling the alloys. It is observed that nitrogen is a more potent solution strengthener than oxygen, which is in turn more effective than carbon. It is thought that the reason behind this is the change in slip tendency from $\{10 \overline{1} 0\}\langle 11 \overline{2} 0\rangle$ prism slip to 


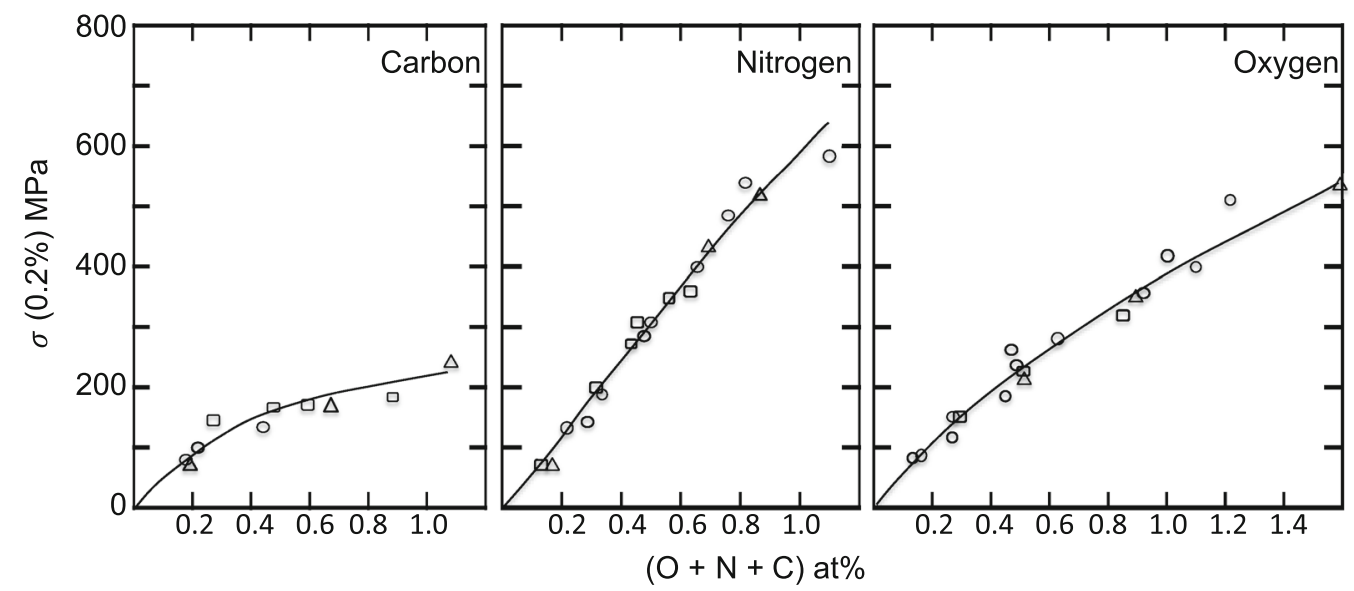

Fig. 1-Effect of dissolved interstitial solid solution elements on yield strength, adapted from Conrad. ${ }^{[7]}$

$\{10 \overline{1} 1\}\langle 11 \overline{2} 0\rangle$ pyramidal slip. Nayak et al. ${ }^{[8]}$ have suggested that the interstitials interact with dislocations due to the production of asymmetric strain fields.

However, less is known about the effect of nitrogen on fatigue performance and this work was performed in order to investigate this question. A series of Ti-6Al-4V-based alloys were prepared and processed to achieve similar microstructures, in order to isolate the effect of $\alpha$ stabilization on microstructure from the underlying alloying effect. Their un-notched fatigue performance was quantified; in addition, fractography and crystallographic orientation analysis was undertaken to assist in the interpretation of the fracture surfaces which might be observed in service components. ${ }^{[9,10]}$

\section{EXPERIMENTAL PROCEDURE}

Stock Ti-6Al-4V aerofoil plate supplied by RollsRoyce plc was re-melted using an Arcast200 vacuum arc melter with nitrogen introduced using powdered titanium nitride in pure titanium foil packets. This re-melted material was then $\beta$ and $\alpha+\beta$ profile rolled to produce $13 \times 13 \mathrm{~mm}$ bars that were then recrystallised, with the temperatures optimized to provide the desired volume fraction of $\alpha_{\mathrm{p}}$. The production route was tailored for each composition to replicate the structure shown in Figure 2.

To achieve this, material from each of the four compositions was globularized and then reheated and water quenched at a variety of temperatures to determine the $\beta$-transus approach curve. It was also necessary to alter the rolling temperatures for each composition due to alloys with higher levels of nitrogen stalling the laboratory rollers at the processing temperatures used for nominal Ti-6Al-4V. It was important to achieve the same rolling reductions to ensure that the same level of strain was experienced by each composition to try and ensure as similar as possible final microstructural conditions.

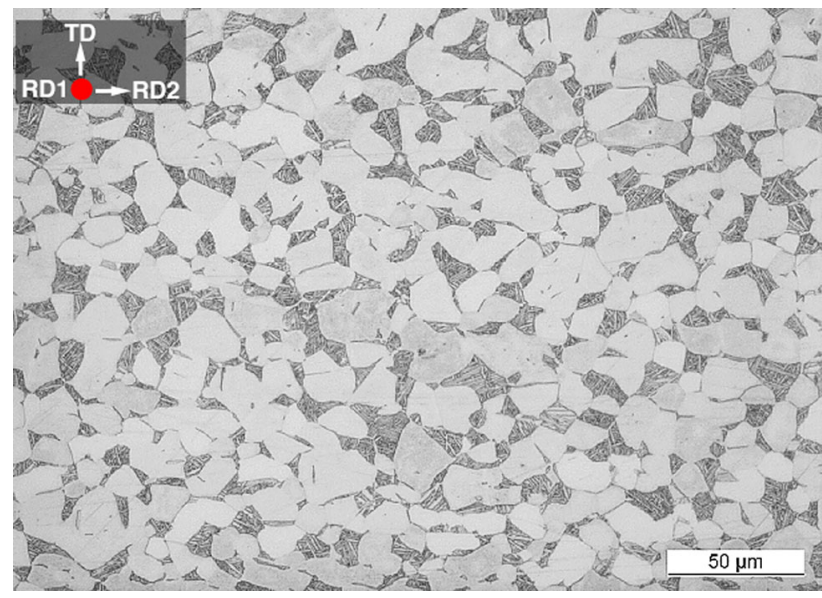

Fig. 2-Optical micrograph showing the microstructure of a reference standard industrial plate product.

The composition of the material was determined using DSIMS (Dynamic Secondary Ion Mass Spectroscopy) depth profiling. Composition analysis in round-robin testing using IGF (Inert Gas Fusion) proved problematic at the nitrogen levels studied, which were above the ASTM standard (ASTM E1409-23 $3^{[1]}$ ) limits for using IGF for nitrogen determination in titanium. The authors have used DSIMS depth profiling in previous work to determine nitrogen levels in Ti-6Al-4V and so had prior knowledge that this method produces reliable and repeatable compositional results when used in conjunction with appropriate reference standards. For this work, a standard from Alpha Resources (AR641 batch 315A) was used, with an interstitial content of $1960 \pm 60 \mathrm{ppmwO}$, $304 \pm 38$ ppmwN, and $39 \pm 6$ ppmwH.

The $\beta$ approach curve was determined metallographically for each composition. Previous studies had given estimates of the effect of nitrogen on the $\beta$ transus in a range of titanium alloys; however, no previous study was found for Ti-6Al-4V. This means that when drawing comparisons to the reference data, the effect of the $\beta$ 
stabilizing alloying addition vanadium must be taken into account. Figure 3 shows the $\beta$ transus approach curves determined from this work with example microstructures shown for each of the four compositions shown in Figure 4. For comparison, predictions made using the titanium database in the PANDAT ${ }^{\mathrm{TM}}$ package are also shown.

Texture measurements were made on samples prepared from the gauge length of tested High Cycle Fatigue (HCF) samples. Samples were prepared from the surface with the sample normal parallel to the rolling

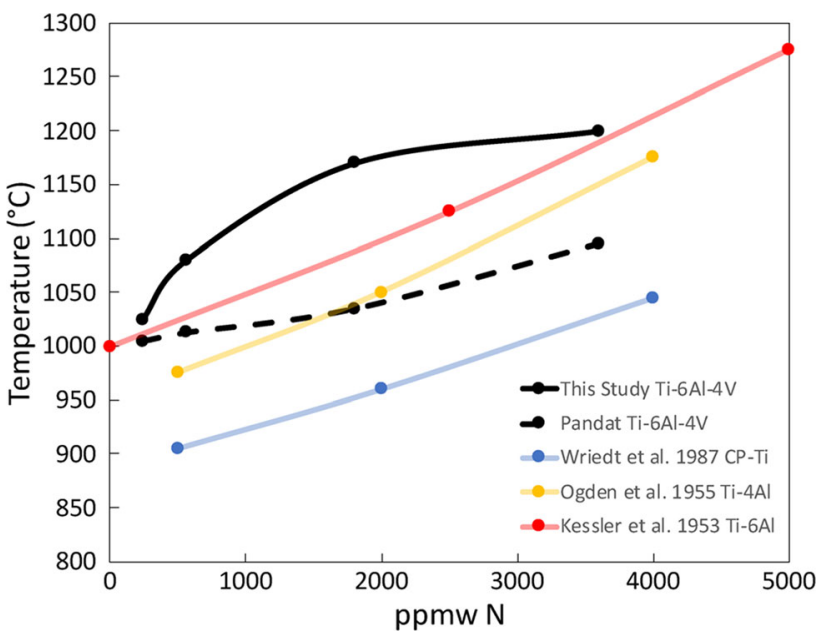

Fig. 3 - $\beta$-transus curves from the literature, PANDAT, and this experimental work (black points). ${ }^{[4,5,13]}$
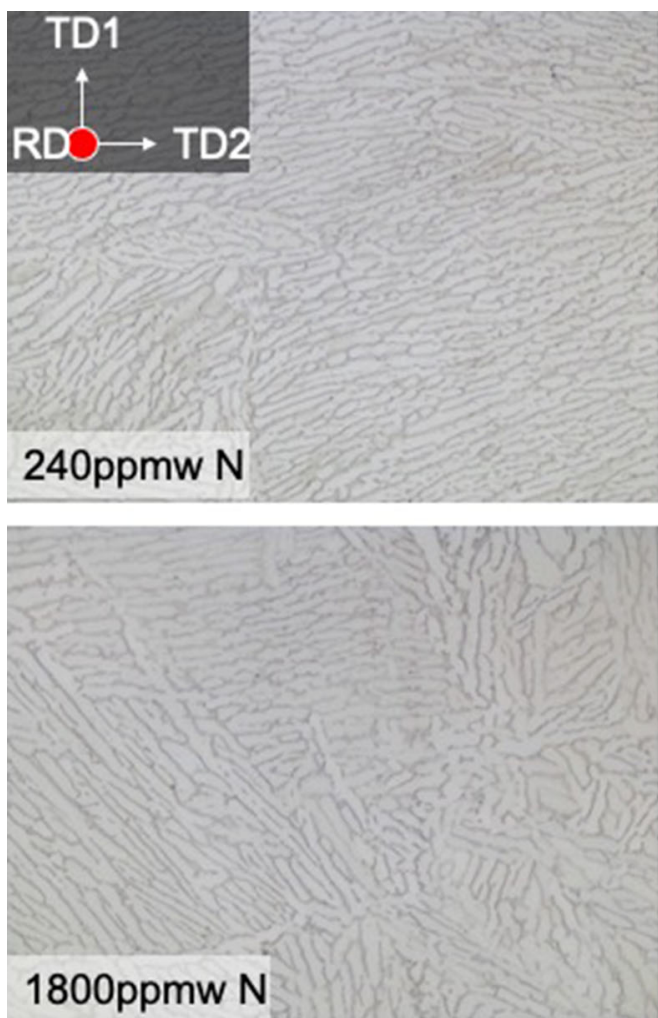

direction of the bar. A Zeiss Sigma VP FEGSEM equipped with an Oxford NordlysMax EBSD detector was used to collect the data, at an accelerating voltage of $20 \mathrm{kV}$. The field of view was chosen to allow for a number of prior $\beta$ grains to be analyzed.

Tensile tests were performed at a nominal strain rate of $1 \times 10^{-3} \mathrm{~s}^{-1}$ on $1.0 \times 1.5 \mathrm{~mm}$ gauge section specimens using a $10 \mathrm{~mm}$ extensometer at room temperature on a 100 kN Zwick/Roell BZC-MM14740.ZW02 electromechanical testing machine (see Figure 5 for the drawing). The extensometer was removed after 5 pct strain and the test run to failure. Hardness testing was undertaken on polished cross-sections from the as-tested gauge length.

Low Cycle Fatigue (LCF) testing was undertaken on round un-notched threaded samples of 240 and 560 ppmwN compositions using a Mayes servo-hydraulic machine with an Instron 8800MT controller. The load regime consisted of an even trapezoidal waveform with a frequency of $0.25 \mathrm{~Hz}$, an $R$-ratio of 0.1 , and a range of peak stress values of 820,790 , and $760 \mathrm{MPa}$.

HCF testing was undertaken on round un-notched threaded samples of all four compositions using an Amsler vibrophore (see Figure 5 for the sample drawing). The load regime consisted of a sinusoidal wave form with a frequency of approximately $85 \mathrm{~Hz}$ and an $R$-ratio of 0.1 . Step testing was utilized with a starting peak stress of $400 \mathrm{MPa}$, a step length of $10^{6}$ cycles, and step height of $50 \mathrm{MPa}$.

Fracture faces from tested $\mathrm{HCF}$ samples were prepared such that EBSD could be undertaken on a polished section perpendicular to the fracture face to allow for a comparison of fractographic features to the
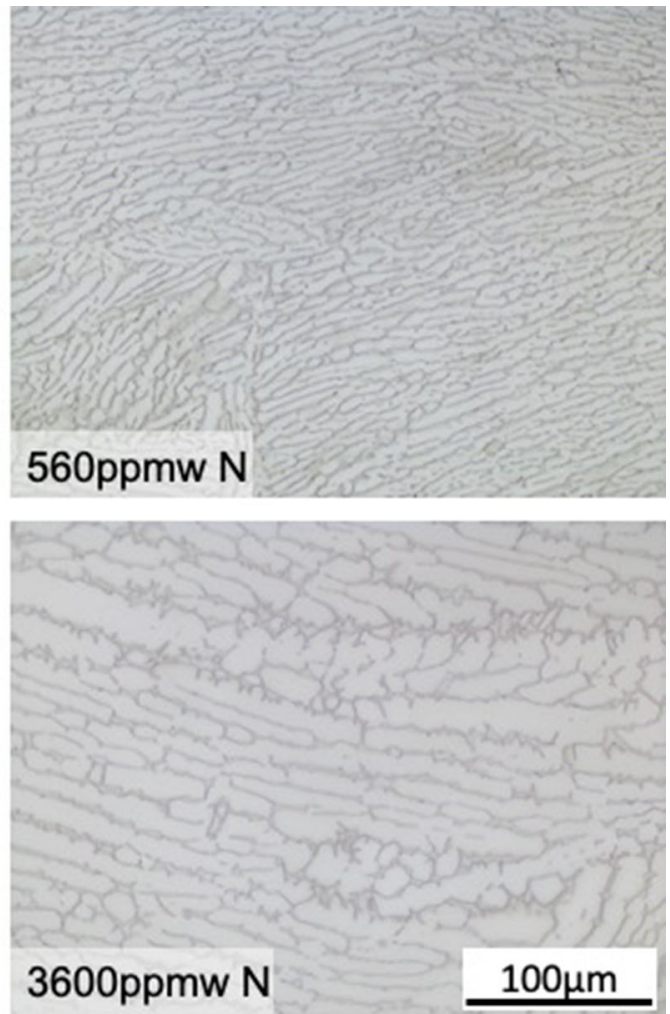

Fig. 4-Optical images showing the microstructures of the four alloys produced. 
35.00
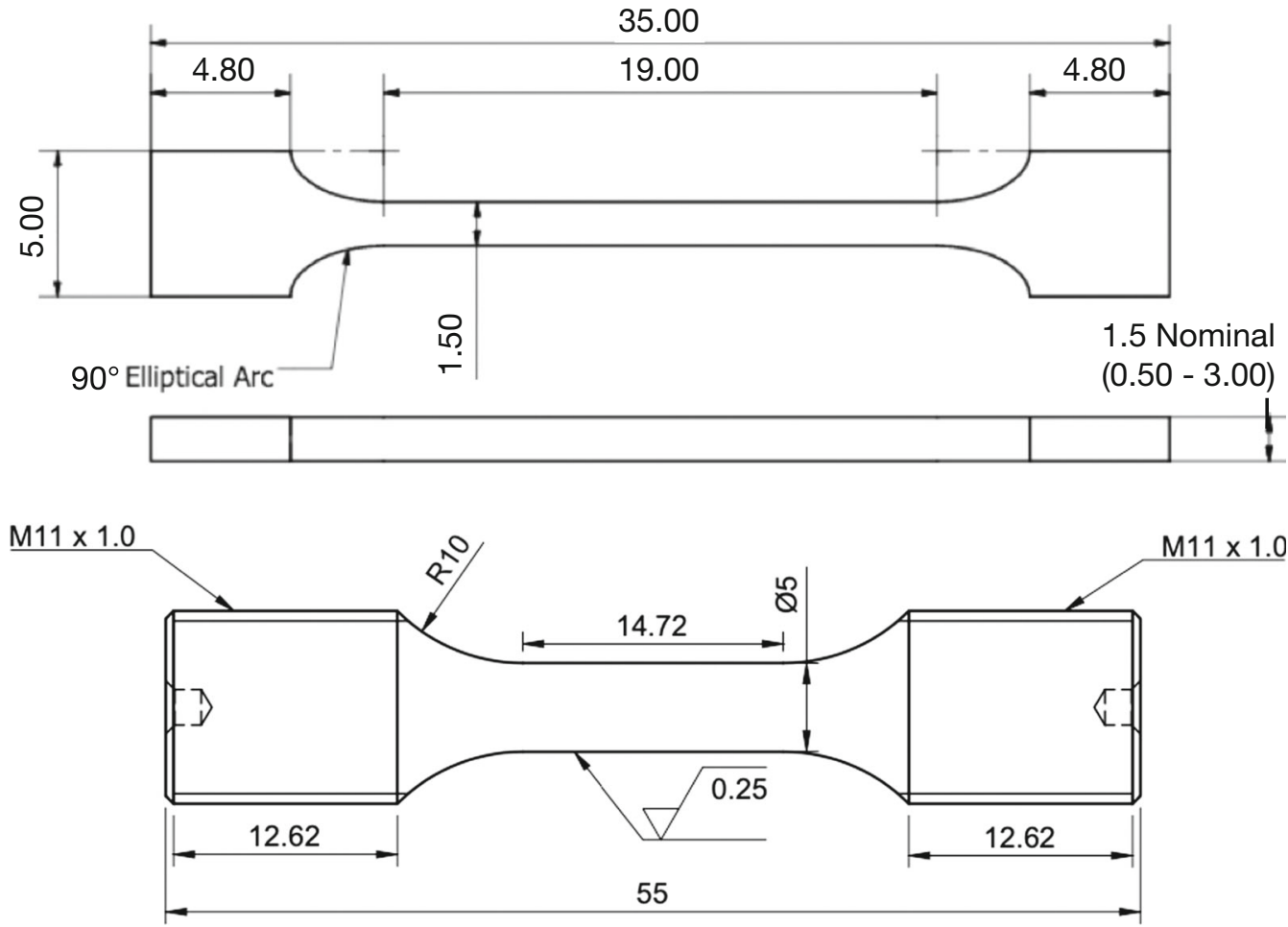

Fig. 5-Tensile and high cycle fatigue specimens used in the present study.

underlying grain orientation. This work was undertaken on 240 and 560 ppmwN for both striated regions and faceted regions with a comparison undertaken on a 3600 ppmwN sample for a faceted region.

\section{RESULTS}

\section{A. Alloy Production}

No evidence could be found of titanium nitride particulate in the product in DSIMS or SEM examination, nor was there any evidence of titanium nitride inclusions at the fatigue crack initiation sites examined. The lack of observed particles suggests that complete dissolution was achieved during the melt stage. Previous work by Van Thyne and Kessler ${ }^{[5]}$ has shown solubility of nitrogen in titanium-aluminum alloys with investigated levels up to $1 \mathrm{wt}$ pct nitrogen. Analysis of the material produced in this study was undertaken by Loughborough Surface Analysis using DSIMS with the results shown in Table I, as discussed earlier the measurements were calibrated against a standard of known composition from Alpha Resources AR641.

The rolled material was globularized at temperatures between $930{ }^{\circ} \mathrm{C}$ and $1055^{\circ} \mathrm{C}$ (chosen to develop high $\alpha_{\mathrm{p}}$ fractions in each of the samples), furnace cooled to $650^{\circ} \mathrm{C}$ and then air cooled. The fraction of $\alpha_{\mathrm{p}}$ present at equilibrium at a series of temperatures was then established by holding at a temperature $T$ for 30 minutes and water quenching, in order to measure the transus curves shown in Figure 3. The transus temperature increased from $1000^{\circ} \mathrm{C}$ at 240 ppmwN (0.08 at. pct) to $1200^{\circ} \mathrm{C}$ at 3600 ppmwN (1.17 at. pct), an
Table I. Measured Oxygen/Nitrogen Compositions Obtained (ppmw, Average and Standard Deviation)

\begin{tabular}{lccc}
\hline Aim N Content & $\mathrm{O}$ & $\mathrm{N}$ & $\mathrm{O}+\mathrm{N}$ \\
\hline Nominal & $2300 \pm 250$ & $240 \pm 140$ & 2500 \\
500 & $2400 \pm 140$ & $560 \pm 90$ & 3000 \\
2000 & $2800 \pm 550$ & $1800 \pm 230$ & 4600 \\
4000 & $2600 \pm 550$ & $3600 \pm 850$ & 6200 \\
\hline
\end{tabular}

Typical nominal Ti-6Al-4V plate product is around $2000 \mathrm{ppmwO}$ and $\leq 300$ ppmwN.

increase of $180 \mathrm{~K} /$ at. pct. As shown in Figure 3, this correlates reasonably well with the literature for Ti-6Al ${ }^{[12]}$ and has a slightly greater sensitivity than in pure titanium. ${ }^{[13]}$ The temperature for 50 pct volume fraction of $\alpha$ phase was found to be less sensitive to nitrogen content, $946^{\circ} \mathrm{C}$ at $240 \mathrm{ppmwN}$ (0.08 at. pct) to $1005^{\circ} \mathrm{C}$ at 3600 ppmwN (1.17 at. pct), an increase of $50 \mathrm{~K} /$ at. pct. The transus curve results provide additional credibility to the DSIMS analysis, as the transus curves follow the same trend.

$\beta$ Rolling temperatures were then picked to be at least $50 \mathrm{~K}$ above the solvus temperature in each alloy, and the $\alpha+\beta$ rolling and globularization temperatures were chosen to be in the region of 40 to 60 pet $\alpha_{p}$ volume fraction. The $\alpha_{\mathrm{p}}$ content present in the final product (Figure 4), was much higher due to $\alpha_{\mathrm{p}}$ growth during furnace cooling from globularization heat treatment. ${ }^{[14]}$ The product microstructures obtained show partially globularized $\alpha_{\mathrm{p}}$ in a matrix of retained $\beta$. The $\alpha_{\mathrm{p}}$ fraction obtained from BSE imaging was 90 pet in the 240 ppmwN alloy and was only very marginally lower at 89 pct in the 3600 ppmwN alloy; however, it was observed 
that the $\alpha_{\mathrm{p}}$ grain size was larger for alloys with higher nitrogen contents. This is important as it illustrates that even 3600 ppmwN may be insufficient to be easily detectable by metallographic examination. Of course, if all the compositions had been processed in the same way, the fraction of retained $\beta$ would decrease with increasing nitrogen content. Compared to a standard plate product (Figure 2), these $\alpha_{\mathrm{p}}$ contents were slightly higher and the $\alpha_{\mathrm{p}}$ grain morphology different, however, the microstructures are felt to be comparable to each other for the purposes of this study. The data in Table II shows the measured average alpha grain width for each of the four compositions.

The texture of each of the four compositions was investigated to see if material that had been mechanically processed in the same manner showed any differences in texture as a function of nitrogen content. Figure 6 shows that there were no obvious differences between the textures of each of the four compositions.

The addition of $500 \mathrm{ppmwN}$ to the source material increased the ultimate tensile strength (UTS) from 980 to $1100 \mathrm{MPa}$ (Figure 7), with a consequent decrease in

Table II. Showing Measured $\alpha_{\mathrm{p}}$ Widths from the Images in Figure 4

\begin{tabular}{lc}
\hline Composition $(\mathrm{ppmwN})$ & $\alpha_{\mathrm{p}}$ Width $(\mu \mathrm{m})$ \\
\hline 240 & 5.4 \\
560 & 7.4 \\
1800 & 6.4 \\
3600 & 9.3 \\
\hline
\end{tabular}
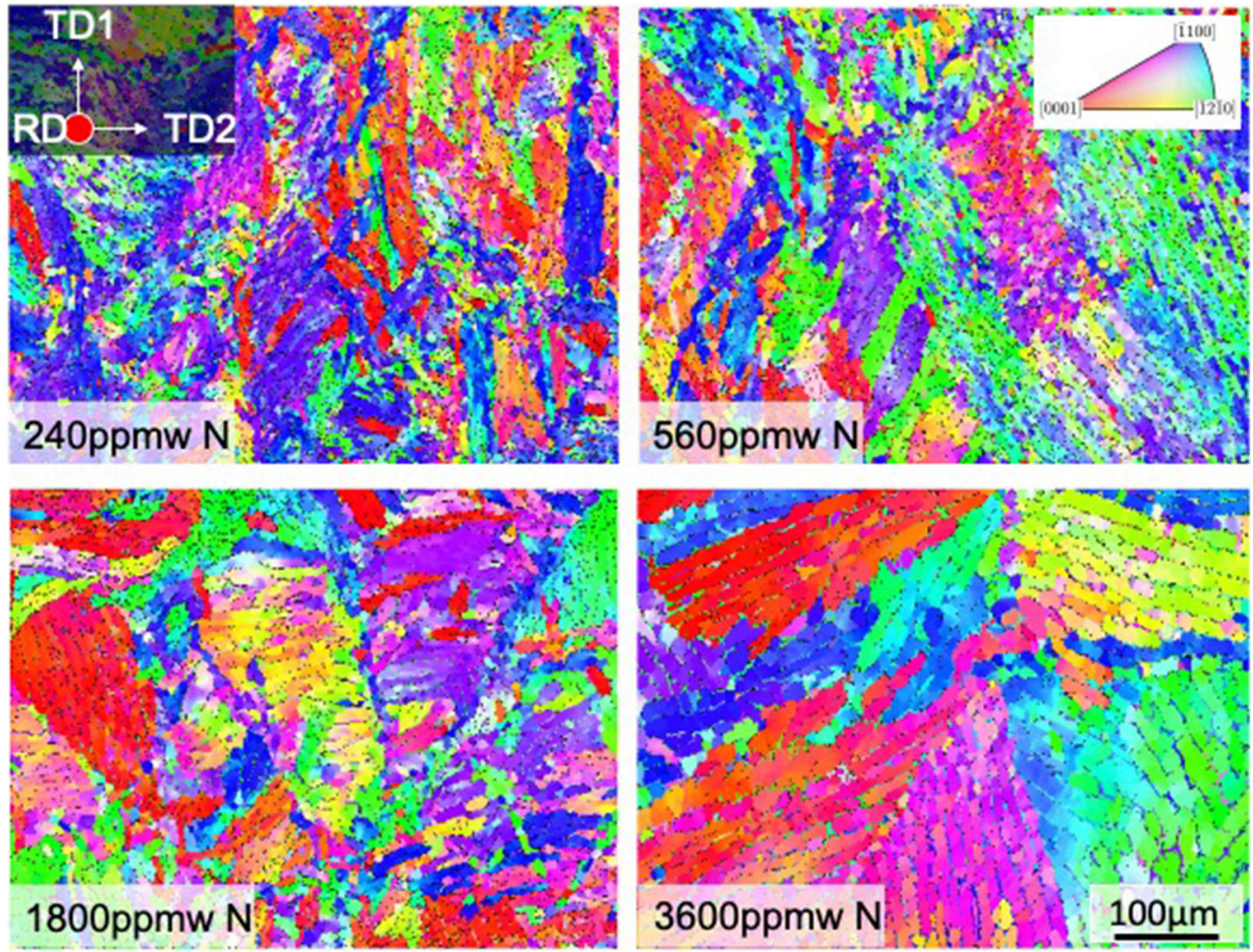

Fig. 6-EBSD maps showing HCP textures of four compositions.

ductility from 10.8 to 3.5 pct. Higher nitrogen additions decreased the ductility further until in the 3600 ppmwN sample, only a failure stress with essentially nil $(0.4 \mathrm{pct})$ ductility was observed, which was lower (890 MPa) than in the baseline material. Industrially, localized increases in oxygen content in solution can sometimes be diagnosed using hardness, for example, see Rugg et al. ${ }^{[15]}$ This can arise in product due to localized heating or atmospheric exposure during service or production, for example. Therefore, the correlation between bulk nitrogen content, hardness, and solvus was also examined (Figure 8). It was observed that the effect of nitrogen on hardness saturated beyond 2000 ppmwN, in the same fashion as the effect on the transus, and therefore hardness in this microstructural condition can be used as an indicator of transus temperature and interstitial content, at least in industrially useful nitrogen ranges.

Nitrogen addition resulted in a marked drop in LCF life, with the addition of 320 ppmwN resulting in a life drop of 40 pet at $820 \mathrm{MPa}$ or, put another way, a drop in strength of $30 \mathrm{MPa}$ at a life of $10^{4}$ cycles (Table III).

The HCF test results are shown in Table IV and Figure 9. HCF step testing consists of repeatedly testing at monotonically higher stresses until failure is observed. At each stress level, a cutoff 'survival' life is used, in this case $10^{6}$ cycles. A clear trend is visible whereby the HCF strength is reduced by the addition of nitrogen. Nicholas ${ }^{[16]}$ defined an HCF strength $\Sigma_{\mathrm{e}}$ from the fraction of the 'survival' cutoff life $N_{\text {fail }} / N_{\text {life }}$ and the stress increment $\Delta \Sigma$ over the preceding stress level $\Sigma_{0}$; 


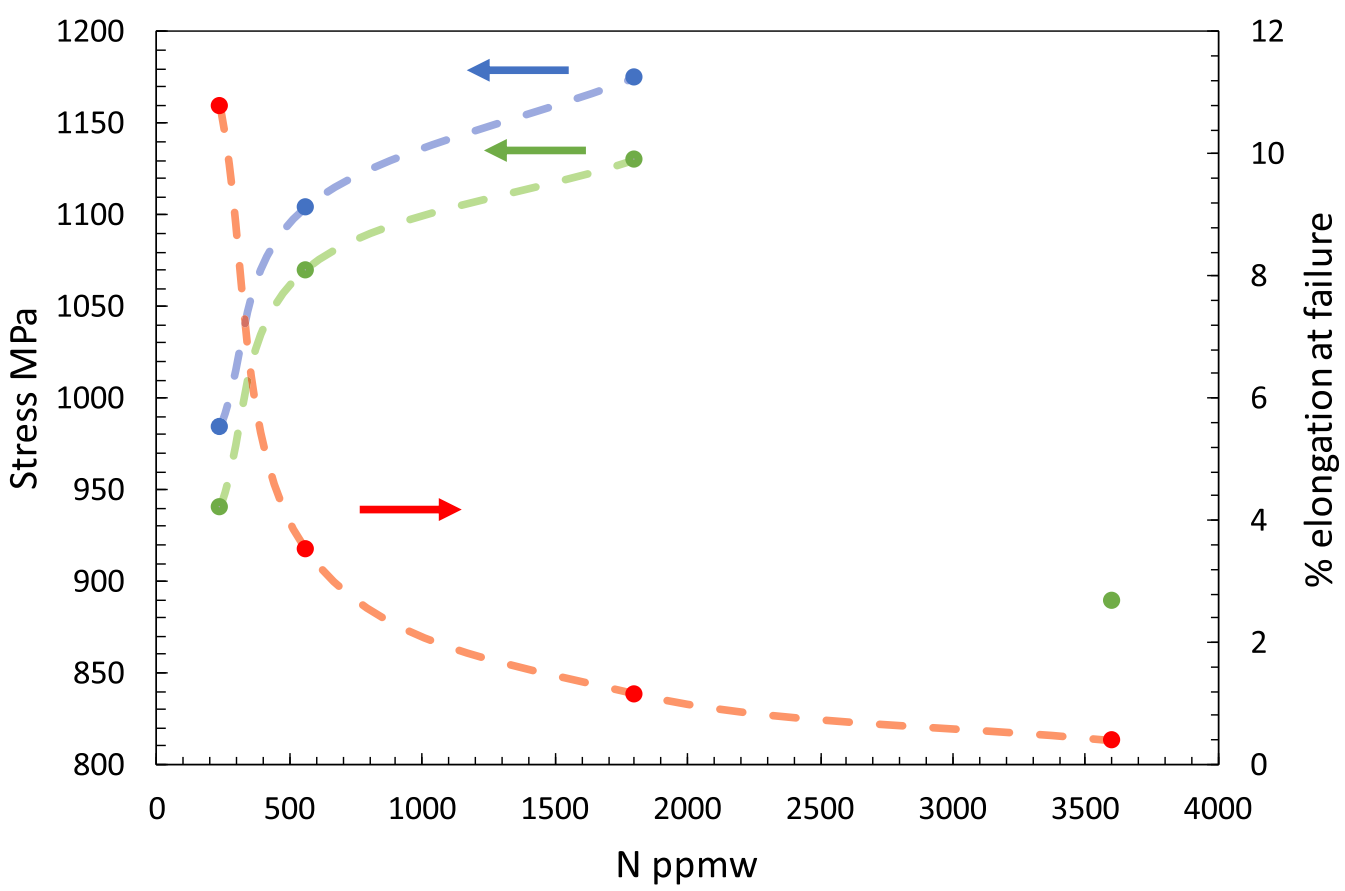

Fig. 7-Effect of nitrogen additions, processed to achieve similar microstructures, on yield strength (green), ultimate tensile strength, UTS (blue), and pct elongation (red) (Color figure online).

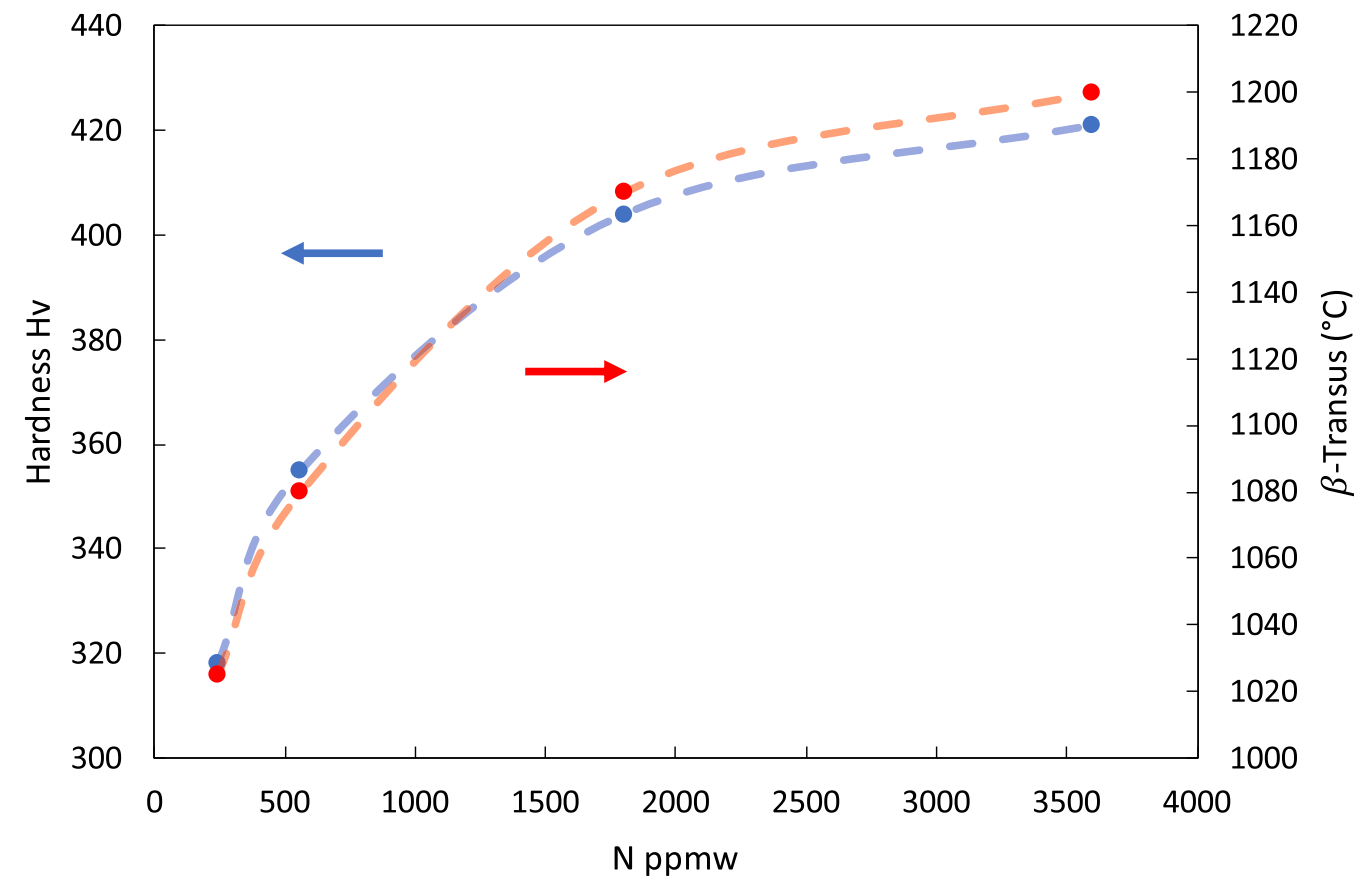

Fig. 8-Effects of $\mathrm{N}$ additions on the $\beta$ transus temperatures, measured metallographically by reheating and quenching globularized material, and on the hardness of materials processed to achieve similar, near-equiaxed microstructures.

$$
\Sigma_{\mathrm{e}}=\Sigma_{0}+\Delta \Sigma \frac{N_{\text {fail }}}{N_{\text {life }}} .
$$

The standard deviation of the inferred HCF strengths were found to be less than 5 pct for each composition. The biggest drop in fatigue strength appears to be between 560 and 1800 ppmwN; possible reasons for this will be discussed subsequently. It is evident that even where similar microstructures are produced even small amounts of contamination by nitrogen can have quite dramatic effects, even within the range of normal Ti-6Al-4V specification (300 ppmwN). This implies that nitrogen contamination due to, e.g., vacuum leaks in production heat treatments can be both 
Table III. Effect of Nitrogen Content on LCF Life at Low Nitrogen Contents Where Reasonable Ductility Remained

\begin{tabular}{lccc}
\hline $\mathrm{N}(\mathrm{ppmw})$ & Test Stress $(\mathrm{MPa})$ & Cycles & Average \\
\hline 240 & 850 & 11,717 & \\
& 820 & 18,874 & 22,300 \\
& & 20,996 & \\
560 & 820 & 26,908 & \\
& & 16,302 & 12,900 \\
& & 10,332 & \\
& 790 & 12,004 & \\
& & 28,900 & 19,000 \\
& & 14,888 & \\
\hline
\end{tabular}

Table IV. Effect of Nitrogen Content of High Cycle Fatigue Test Lifetime and HCF Strength

\begin{tabular}{|c|c|c|c|}
\hline $\begin{array}{l}\mathrm{N} \\
\text { (ppmw) }\end{array}$ & $\begin{array}{l}\text { Failure Step } \\
\quad(\mathrm{MPa})\end{array}$ & Cycles & $\begin{array}{l}\text { HCF Strength } \\
(\mathrm{MPa})\end{array}$ \\
\hline Commercial & 600 & 208,300 & 560 \\
\hline \multirow[t]{2}{*}{ Product } & 600 & 79,300 & 554 \\
\hline & & average & $557 \pm 3$ \\
\hline \multirow[t]{5}{*}{240} & 500 & 688,800 & 484 \\
\hline & 500 & 951,300 & 498 \\
\hline & 500 & 448,600 & 472 \\
\hline & 450 & 847,900 & 442 \\
\hline & & average & $474 \pm 24$ \\
\hline \multirow[t]{5}{*}{560} & 450 & 280,200 & 414 \\
\hline & 450 & 329,100 & 416 \\
\hline & 450 & 639,900 & 432 \\
\hline & 450 & 722,100 & 436 \\
\hline & & average & $425 \pm 10$ \\
\hline \multirow[t]{5}{*}{1800} & 400 & 803,300 & 390 \\
\hline & 400 & 662,000 & 383 \\
\hline & 400 & 741,500 & 387 \\
\hline & 400 & 869,800 & 393 \\
\hline & & average & $388 \pm 5$ \\
\hline \multirow{5}{*}{3600} & 400 & 196,900 & 360 \\
\hline & 400 & 224,800 & 361 \\
\hline & 400 & 245,100 & 362 \\
\hline & 400 & 100,500 & 355 \\
\hline & & average & $360 \pm 4$ \\
\hline
\end{tabular}

undetectable even by batch testing and sectioning of samples for optical microscopy, and have significant effects on lifetime hence, there being atypical requirement to remove material from the surface of a component during production.

An example fracture face of each composition was examined in detail and striation counting was undertaken where applicable. Examination via optical microscopy showed clear differences between the four compositions, with the 1800 and 3600 ppmwN fractures having a greater level of relief in comparison to the other samples. Striated growth was observed in areas on both

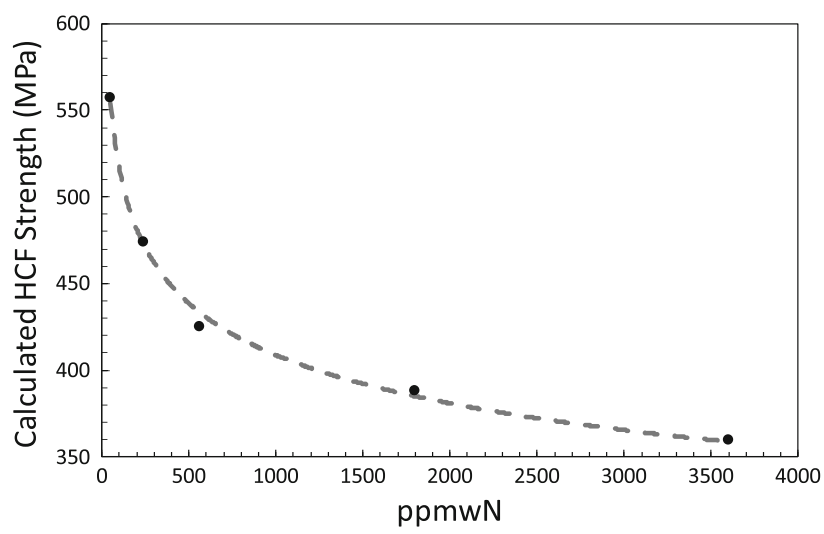

Fig. 9-Effect of nitrogen additions (ppmwN) on calculated HCF strength, inferred from the HCF step test data. The value at 50 ppmwN is for commercial reference material.

the 240 and 560 ppmwN fractures interspersed with fatigue facets. The fracture faces from 1800 and 3600 ppmwN samples did not contain any areas of striated growth. These fracture faces were dominated by colonies of macroscopic fatigue facets that had propagated along the elongated $\alpha_{\mathrm{p}}$ grains present in their microstructures.

When the sample of composition 240 ppmwN was investigated, it was found that striated regions of the fracture were orientated such that the crack had grown through $\alpha_{\mathrm{p}}$ angled close to the $\{12 \overline{1} 0\}$ plane (Figure 10), as would be expected. Comparison with a fracture from a 560 ppmwN sample showed that striated growth occurred on the $\{\overline{1} 100\}$ plane of the $\alpha_{\mathrm{p}}$ grains with faceted growth on $\{0001\}$ planes. Further comparison was made with a sample of $3600 \mathrm{ppmwN}$ as that sample did not exhibit any striated growth; the results of that analysis showed that similar to the 560 ppmwN sample, the faceting occurred close to the $\{0001\}$ plane (Figure 11).

\section{DISCUSSION}

\section{A. Composition}

The accurate measurement of dissolved nitrogen is crucial to this work, but can be challenging. The established technique for measuring interstitial elements in titanium is IGF, using e.g., a LECO analyser, however measurements carried out using this technique did not give results in line with expectations from the melt compositions. It is thought that this was due to the values of nitrogen introduced during alloy production being outside of the calibration range of the technique. ASTM E1409-13 ${ }^{[1]}$ is the relevant standard and gives 

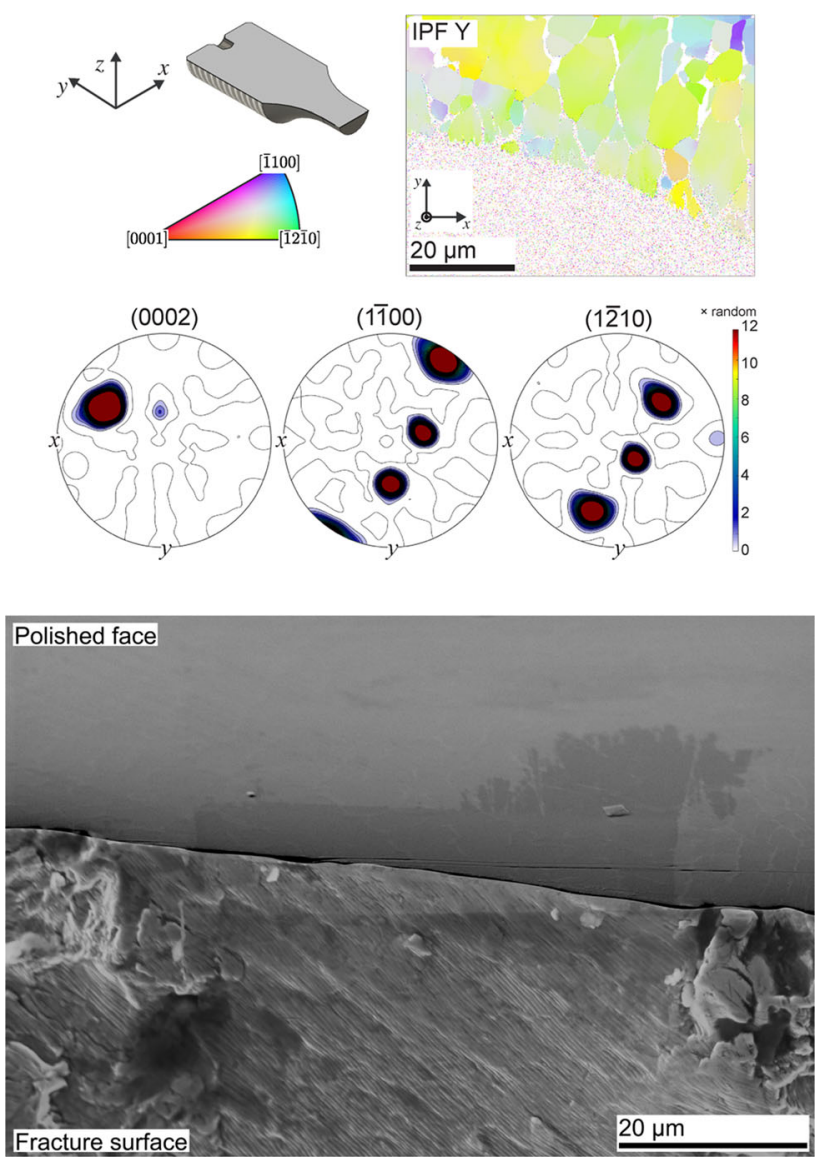

Fig. 10-Fractographic vs texture EBSD mapping for HCF step-tested sample of 240 ppmwN.

detection limits of 100 to 500 ppmw for oxygen and 30 to $1100 \mathrm{ppmw}$ for nitrogen. These compare to an intended range of 1800 to 2300 ppmw oxygen and 50 to 4000 ppmw nitrogen for this work. In contrast, the use of DSIMS reported here requires a calibrated standard as close as possible in composition to the samples being measured. A calibration sample was obtained from Alpha Resources with a composition very close to one of the intended compositions. This standard was certified using IGF calibrated to ASTM E1409-13, from a supplier certified to be compliant with ISO guide $31,{ }^{[17]}$ ISO $17034: 2016^{[18]}$ and ISO/IEC $17025^{[19]}$ One of the primary standards used for calibration by the supplier is BCR-059; this certified reference material was been measured 106 times for the nitrogen quantification as part of the BCR-059 ${ }^{[20]}$ round-robin. The methods used by the measuring laboratories included: $14 \mathrm{MeV}$ neutron activation analysis, reducing fusion, Triton activation analysis, Surface analysis by prompt $(\mathrm{d}, \mathrm{p})$ reaction, the Kjeldahl method, Heat extraction, charged particle
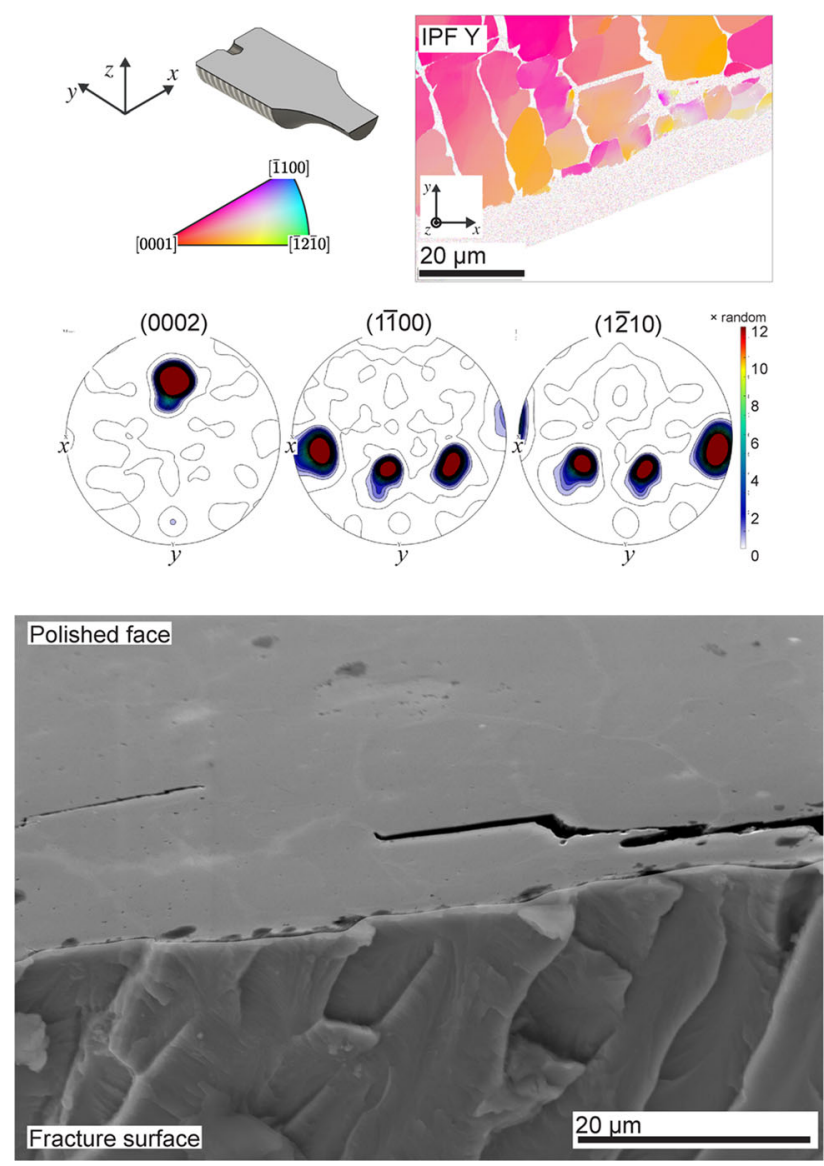

Fig. 11-Fractographic vs. texture EBSD mapping for HCF step-tested sample of $3600 \mathrm{ppmwN}$.

activation analysis, fast neutron activation analysis, photon activation analysis and surface analysis by measurement of charged particles from nuclear reactions.

A further question is around the solubility of nitrogen in Ti-6Al-4V. Jaffee's discussion ${ }^{[6]}$ of the solubility of nitrogen in the $\alpha$-titanium phase suggests the solubility limit is 18.7 at. pct or $6.3 \mathrm{wt}$ pct; Conrad ${ }^{[7]}$ suggests 19 at. pet or $7.2 \mathrm{wt}$ pct. In this study we reached a maximum of 1.17 at. pct and $0.36 \mathrm{wt}$ pct, well below the suggested solubility limit; this is further supported by the absence of observation titanium nitride precipitate on the fracture faces of the tested samples.

\section{B. Tensile and Basic Mechanical Properties}

Nitrogen shows similar trends to oxygen in its strengthening effects on titanium alloys, as would be expected from previous studies that have shown them 
both to be $\alpha$ stabilizing interstitials. It has been reported by Ogden et al. ${ }^{[4]}$ that the effects of nitrogen can be taken to be twice as potent as oxygen. It was observed that a limit was reached after which increases in nitrogen content resulted in a plateau and then a drop in strength, similar to oxygen. However, it is unclear whether this is a result of the level of just nitrogen or the combined interstitial content.

Hardness was observed to increase at a rate of 305 $\mathrm{H}_{\mathrm{v}} /$ wt pct $\left(95 \mathrm{H}_{\mathrm{v}} /\right.$ at. pct). McKinley ${ }^{[21]}$ found in pure titanium (with $0.065 \mathrm{wt}$ pet $\mathrm{O}$ ) that the hardness increased at $567 \mathrm{H}_{\mathrm{v}} / \mathrm{wt}$ pct $\left(160 \mathrm{H}_{\mathrm{v}} /\right.$ at. pct $)$. Ogden et $a .^{[4]}$ suggested that at room temperature these interstitial element additions have little effect on tensile ductility in pure titanium but they did also suggest that they have a negative effect on toughness. When they examined titanium-aluminum binary alloys they observed that additions of nitrogen had a much greater effect on ductility. In the present study, alloys with $>1000$ ppmwN possessed only very limited ductility.

In terms of fabricability, Ogden et al. ${ }^{[4]}$ suggest that although the effect of interstitials on the strength of titanium alloys decreases as temperatures reach $650{ }^{\circ} \mathrm{C}$ (which is around the temperature at which $\alpha_{2}$ would dissolve, if present), their effect on strain rate sensitivity remains which will affect the primary mechanical processing parameters as these are high strain rate deformation processes. This was noticed when rolling the four compositions during this work, as the temperatures used to achieve the same rolling reduction route across the compositions were quite different, in line with the change in $\beta$-transus.

\section{Fatigue Lifetimes}

Clear conclusions can be drawn as to the effect of nitrogen on the fatigue properties of Ti-6Al-4V; both the LCF and HCF testing carried out in this work show that

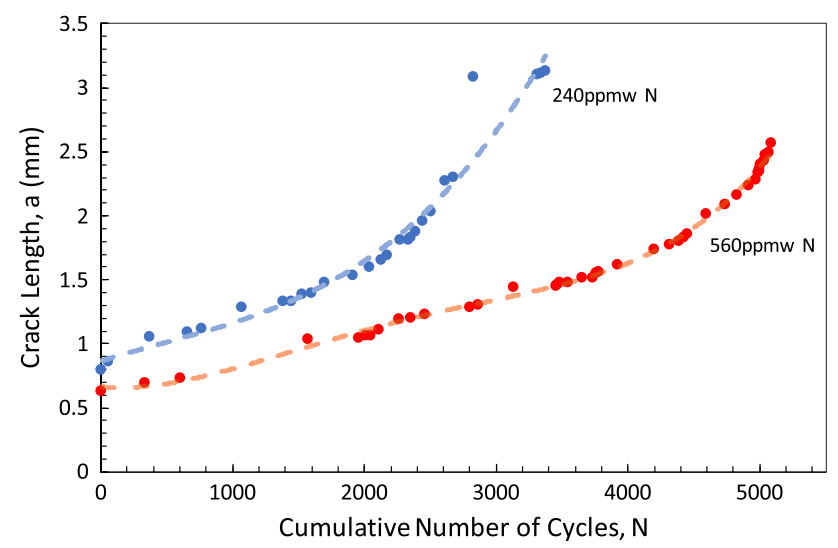

Fig. 12-Striation count data from HCF step-tested samples containing 240 (in blue) and $560 \mathrm{ppmwN}$ (in red) (Color figure online). nitrogen has a negative effect on the fatigue strength of Ti-6Al-4V. As with the change in tensile properties, in particular the trend in the HCF strength results show a rapid initial drop-off which stabilizes with further nitrogen additions. Striation counting ${ }^{[22]}$ is a technique where the striation density is evaluated repeatedly at different crack lengths and the number of cycles then inferred by integration, assuming a one-to-one correspondence of striations to cycles. Particular care is required where the striation spacing is small $(<50 \mathrm{~nm})$ or where $K_{\max }$ approaches $K_{1 \mathrm{c}}$. Only the 240 and 560 ppmwN samples were appropriate to examine by this approach due to a lack of striations on the other compositions. Up to around 1500 cycles (from first striated growth) the growth rates were similar between these materials (Figure 12), but after this the crack growth rates diverged, with the higher nitrogen, stronger material showing slower fatigue crack growth.

\section{Fatigue Fractography}

The samples with a higher nitrogen level exhibited a suppression of striated growth (promotion of faceted growth). On the samples with lower levels of nitrogen, large areas of the fracture face were striated; these regions covered many $\alpha_{\mathrm{p}}$ grains which were visible through the striations. These large areas (greater than $2 \times 2 \mathrm{~mm}$ ) are thought to be of greater size than the prior $\beta$ grains, which suggests that either adjacent prior $\beta$ grains were of similar orientation, or that the colonies that formed from them selected similar variants. Alternatively, the $\Delta K$ at the crack depths where these striated regions were observed was sufficiently high to overcome the restriction that orientation places on striation formation in less favorable orientations.

The results of the striation counting exercise are interesting as the two curves show the reverse of what had been expected prior to undertaking the counts. With the reduction in plasticity observed in the tensile tests of the 560 ppmwN composition it was expected that the fatigue sample of that composition would have a faster crack growth rate; that is not what has been observed through the striation counts which show that the sample of 560 ppmwN composition started to striate earlier and kept a slower propagation rate whilst also growing for longer before reaching $K_{1 \mathrm{c}}$. It is postulated that the reason for this is that the $\mathrm{HCF}$ tests were all carried out following the same step loading regime, which in this case would mean that the test was undertaken at a lower proportion of the material's strength. The 560 ppmwN composition sample failed on a step where the maximum load was $450 \mathrm{MPa}$ which is approximately 40 pct of that composition's UTS, whereas the 240 ppmwN composition sample failed at a max load of $500 \mathrm{MPa}$ which is approximately 50 pet of that composition's UTS. The observation that compositions with higher nitrogen contents exhibited a lower crack growth rate but also 

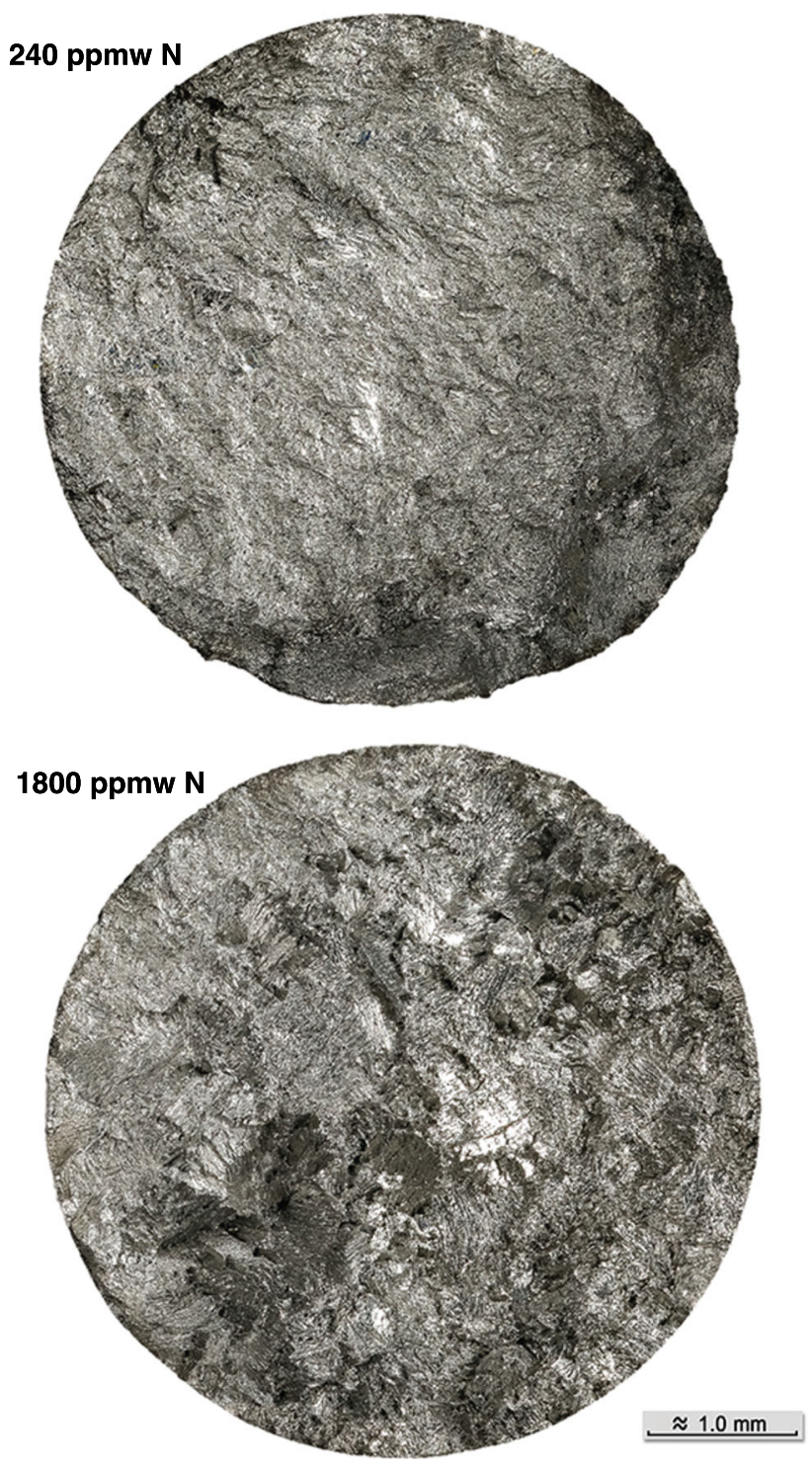

Fig. 13- Optical overviews of a fracture face from HCF samples of 240 and 1800 ppmwN

had lower lives, implies that the main effect of nitrogen contamination is to lower the number of cycles to crack initiation.

There was a dramatic difference between the fracture appearance of the 240 and 560 ppmwN samples, and the 1800 and 3600 ppmwN samples; for the sake of brevity only the 240 and 3600 ppmwN fracture surfaces are shown, in Figures 13, 14 and 15. The 240 ppmwN sample shows a fracture appearance typical of nearequiaxed Ti-6Al-4V fatigue. In the initiation (blue and green) region, the crack has a relatively flat appearance but with evidence of plasticity and linear features along the direction of crack growth within each apparently faceted primary alpha grain. Once the crack grows into the conventional Paris regime, striated fatigue crack growth dominated in most grains orientations ${ }^{[9,10]}$; the underlying $\alpha / \beta$ microstructure is still visible but within a colony, well-formed striations were observed.

The higher nitrogen-containing samples showed ductile feathered fatigue faceting following the colonies of $\alpha_{\mathrm{p}}$ grains (from the prior $\beta$ grains) with large secondary cracks between these colonies. It was observed that across all orientations at all crack depths, only facets were observed, i.e., even prismatic and pyramidal grains faceted regardless of the local $\Delta K$ at the time of failure. The feathering on the facets is uniform in its directionality within each colony, suggesting that the orientation of those colonies dominated the growth direction. The amount of feathering was much lower in the initiation region, which was only barely subsurface, than it was further along the crack length. The fracture surface as a whole showed a much rougher surface, but actually a fairly substantial region of fatigue crack growth rather than simply tensile fracture. The abundant plasticity on the fracture surface suggests that a view of nitrogen-containing titanium as simply being brittle is rather deceptive. Rather, once plasticity and cracking occur, crack growth is quite rapid, suggesting either limited ductility before exhaustion occurs or a reduction in work hardening rate leading to more rapid cracking, or both; in either case it is clear that this reduction in ductility is associated with much plastic deformation.

\section{CONCLUSIONS}

The effect of nitrogen additions on the fatigue behavior of Ti-6Al-4V has been examined in a series of test bars that were processed to achieve nominally identical, near-equiaxed microstructures. The following conclusions can be drawn.

(1) Nitrogen additions increased the beta transus temperature, while also increasing the required level of strain to break up the microstructure during hot processing. Increasing the nitrogen content up to around 560 ppmwN shows a benefit to UTS with a small trade-off in ductility; 

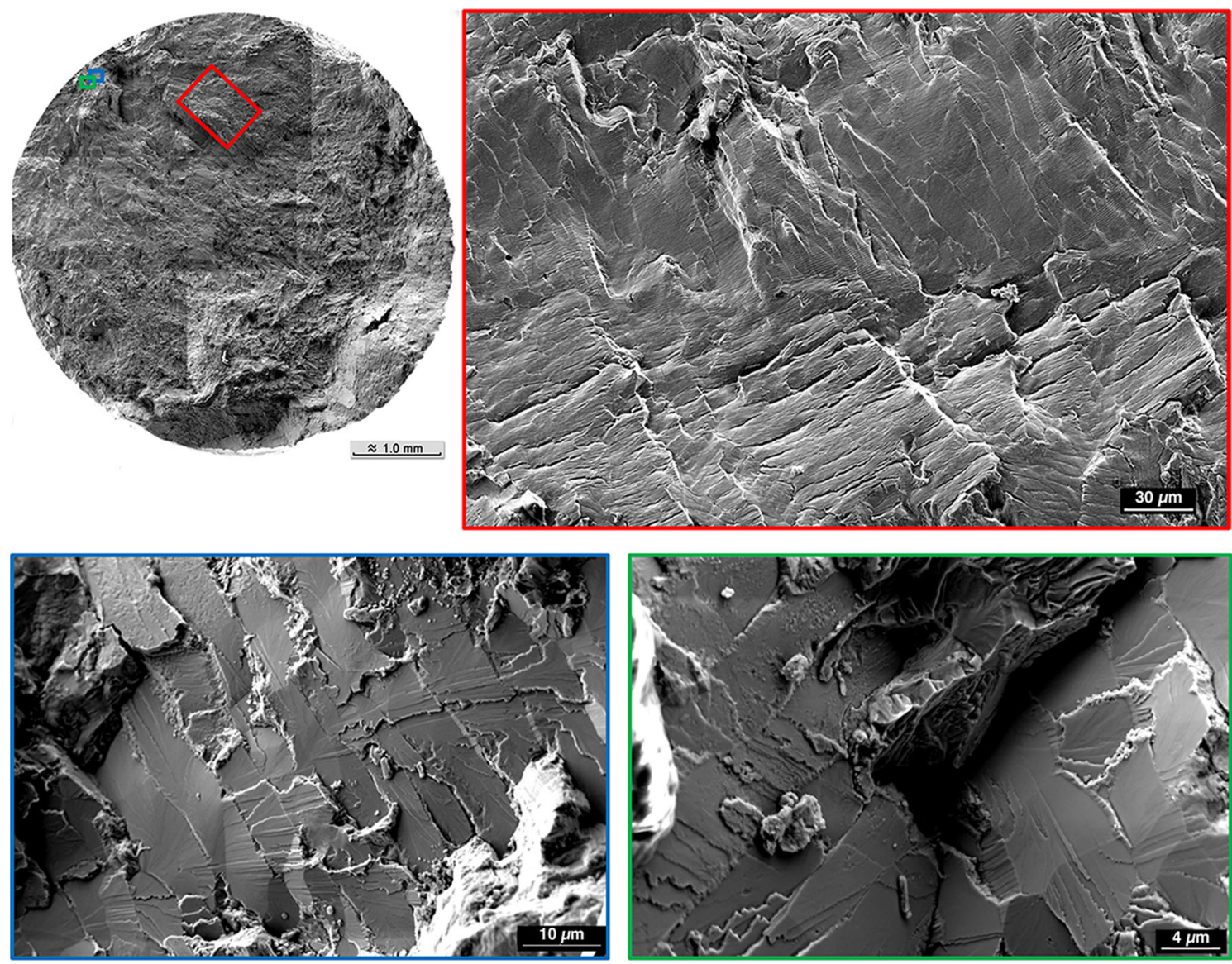

Fig. 14 - SEM fractographs of a HCF step-tested sample of 240 ppmwN composition. The fracture appearance at the initiation (green and blue) is shown, in contrast to the subsequent conventional striated fatigue crack growth regime at longer crack lengths (red) (Color figure online).

however, beyond this point, unacceptably low levels of ductility remained.

(2) In $R=0.1$ testing at $820 \mathrm{MPa}$, low cycle fatigue endurance approximately halved from 22,000 to 13,000 cycles with doubling of nitrogen content from 240 to 560 ppmw. Similarly, a continuous decrease in HCF strength at the $10^{6}$ cycle level was observed, from around $560 \mathrm{MPa}$ in commercial product to around $360 \mathrm{MPa}$ in heavily nitrogen-contaminated (3600 ppmw) material. No lower bound of additional nitrogen content was observed that did not have a detrimental effecteven levels of 240 and 560 ppmw showed a deficit compared to commercial product, and the effect of nitrogen on HCF strength per at. pct was greater at smaller levels of addition, inversely following the effects on strength.
(3) The HCF fracture surfaces in the samples with only small nitrogen additions were similar to those observed in conventional product, as previously reported by Bantounas et al., with striated fatigue crack growth in grains well oriented for $\langle a\rangle$ slip, but relatively flat fractography near the initiation site, which was just subsurface, although still with some evidence of plasticity. In contrast, at high nitrogen contents, $1800 \mathrm{ppmw}$ and above, the fracture surfaces showed a macroscopically rougher and more brittle appearance was observed, but with extensive evidence of ductility running along the length of each $\alpha_{p}$ plate and no observation of conventional striations that would aid in post hoc fatigue crack growth lifetime assessment. 

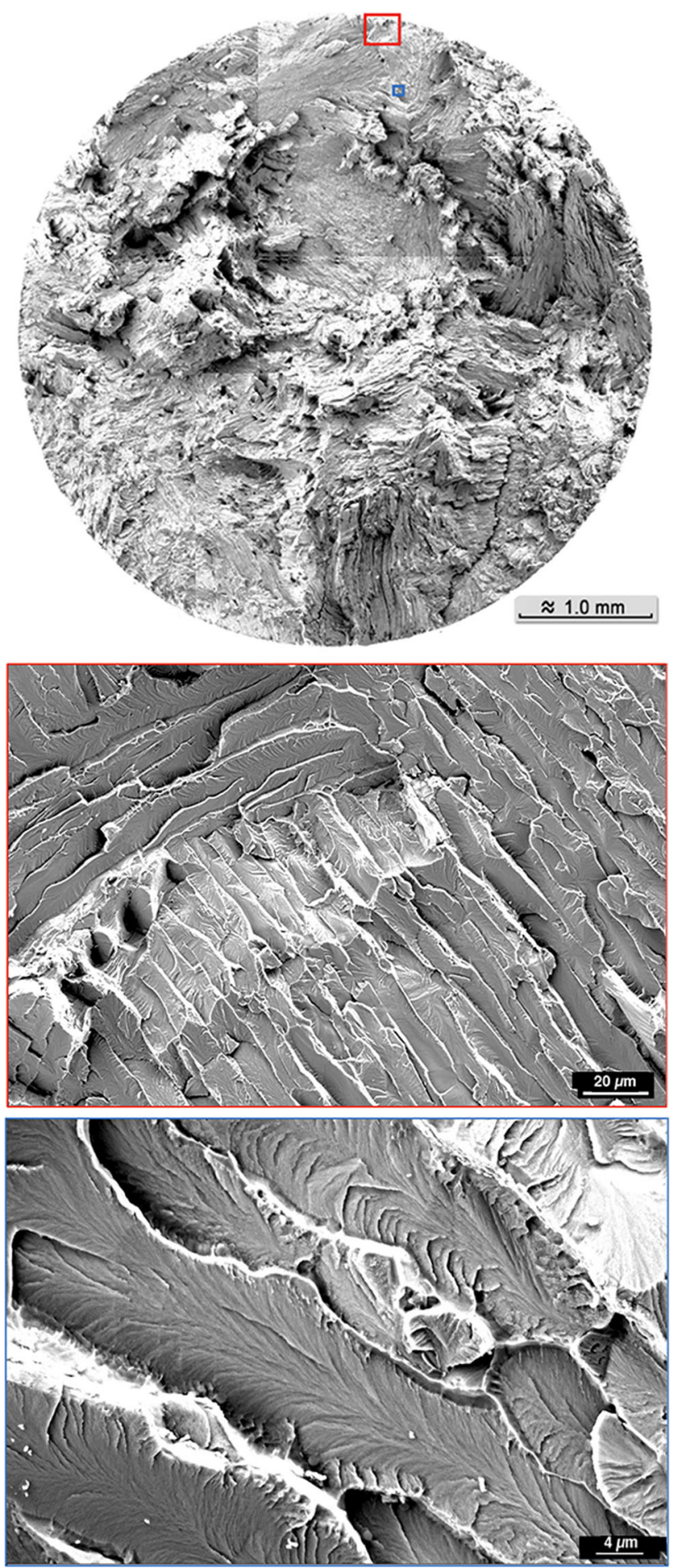

Fig. 15-SEM fractographs showing a variety of views of the fracture face from a HCF sample of 3600 ppmwN composition (Color figure online).

Therefore, metallographic microstructure examination is not necessarily a reliable indicator of an absence of deleterious nitrogen contamination in surfaces; given the difficulty of measuring low levels of nitrogen in the electron microscope, this should be carefully recalled when assessing fracture initiation in potentially $\mathrm{N}$-affected components.

\section{ACKNOWLEDGMENTS}

This work was funded by Rolls-Royce plc. (CRC Studentship and Time) and under the Hexmat EPSRC Programme Grant EP/K034332/1 (DD Time). The assistance of Loughborough Surface Analysis (LSA) with the DSIMS nitrogen content measurement; $\mathrm{Mr}$. Jonathan Green with the macrophotography, Rolls-Royce plc.; and Dr. Mezan Rahman, Dr. Ioannis Bantounas, and Mr. Ben Wood at Imperial are gratefully acknowledged.

\section{OPEN ACCESS}

This article is licensed under a Creative Commons Attribution 4.0 International License, which permits use, sharing, adaptation, distribution and reproduction in any medium or format, as long as you give appropriate credit to the original author(s) and the source, provide a link to the Creative Commons licence, and indicate if changes were made. The images or other third party material in this article are included in the article's Creative Commons licence, unless indicated otherwise in a credit line to the material. If material is not included in the article's Creative Commons licence and your intended use is not permitted by statutory regulation or exceeds the permitted use, you will need to obtain permission directly from the copyright holder. To view a copy of this licence, visit http://creat ivecommons.org/licenses/by/4.0/.

\section{REFERENCES}

1. R.O. Ritchie: Metall. Trans. A, 1977, vol. 8, pp. 1131-39

2. A. McQuillan and M. McQuillan: Metallurgy of the Rarer Metals No. 4: Titanium, 1st ed., Butterworths Scientific Publications, London, 1956.

3. W. Finlay and J. Snyder: Trans. Am. Inst. Min. Metall. Eng., 1950, vol. 188 , p. 277

4. R. Ogden, H.R. Jaffee, and D. Maykuth: Trans. Am. Inst. Min. Metall. Eng., 1950, vol. 188, p. 1261.

5. R.J. Van Thyne and H.D Kessler: Trans. Am. Inst. Min. Metall Eng., 1954, vol. 200, p. 193.

6. R. Jaffee: Prog. Met. Phys., 1958, vol. 7, pp. 65-163.

7. H. Conrad: Prog. Mater. Sci., 1981, vol. 26, pp. 123-403.

8. S.K. Nayak, C.J. Hung, V. Sharma, S.P. Alpay, A.M. Dongare, W.J. Brindley, and R.J. Hebert: NPJ Comput. Mater., 2018, vol. 4, p. 11.

9. I. Bantounas, T. Lindley, D. Rugg, and D. Dye: Acta Mater., 2007, vol. 55, pp. 5655-65.

10. I. Bantounas: Microtexture and High Cycle Fatigue Cracking in Ti-6Al-4V. Ph.D. Thesis, Imperial College London, 2008.

11. ASTM E1409-13: Standard Test Method for Determination of Oxygen and Nitrogen in Titanium and Titanium Alloys by Inert Gas Fusion, ASTM Standards, 2013, pp. 1-7.

12. H.D. Kessler, W. Roster, R.J. Van Thyne, Titanium Phase Diagrams. Armour Research Foundation, WADC Technical Report 52-335, 1953. Available from https://apps.dtic.mil/dtic/tr/fulltext/ u2/029976.pdf.

13. H.A. Wriedt and J.L. Murray: Bull. Alloy Phase Diagr., 1987, vol. 8, pp. 378-88.

14. C. Dichtl, Z. Zhang, H. Gardner, P. Bagot, A. Radecka, D. Dye, M. Thomas, R. Sandala, J.Q. da Fonseca, and M. Preuss: Mater. Charact., 2020, vol. 164, p. 110327.

15. D. Rugg, T.B. Britton, J. Gong, A.J. Wilkinson, and P.A. Bagot: Mater. Sci. Eng. A, 2014, vol. 599, pp. 166-73. 
16. T. Nicholas: High Cycle Fatigue: A Mechanics of Materials Perspective, Elsevier, Amsterdam, 2006.

17. ISO: ISO GUIDE 31:2015 Reference Materials-Contents of Certificates, Labels and Accompanying Documentation. Technical Report, ISO, 2015.

18. ISO: ISO 17034:2016 General Requirements for the Competence of Reference Material Producers. Technical Report, ISO, 2016.

19. ISO: ISO/IEC 17025:2017 General Requirements for the Competence of Testing and Calibration Laboratories. Technical Report, ISO, 2017.
20. J. Pauwels: BCR-059 the Certification of Oxygen in Non-ferrous Metals. Technical Report, Joint Research Centre-Central Bureau for Nuclear Measurements, Geel, 1979.

21. T.D. McKinley: J. Electrochem. Soc., 1956, vol. 103, p. 561.

22. P.H. DeVries, K.T. Ruth, and D.P. Dennies: J. Fail. Anal. Prev., 2010, vol. 10, pp. 120-37.

Publisher's Note Springer Nature remains neutral with regard to jurisdictional claims in published maps and institutional affiliations. 